\title{
Creative teaching behaviors of health care school teachers in Taiwan: mediating and moderating effects
}

\author{
Hsing-Yuan Liu ${ }^{1,2^{*}}$ (D) and I-Teng Wang ${ }^{1}$
}

\begin{abstract}
Background: Considerable attention has been paid to the variables for creative abilities of teachers and the creative climate of the schools in which they teach, as well as the direct relationships between these variables. However, research on the indirect links between these variables concerning creativity in higher education has been limited. Researches on creative teaching behaviors among health care teachers are scant, particularly in Taiwan.
\end{abstract}

Methods: This study used a cross-sectional descriptive design to investigate potential mediating and moderating effects of Taiwanese health care school teachers' creative teaching self-efficacy and a school's creative climate, the relationship between these variables, and the relationship between creative teaching self-efficacy and creative teaching behaviors. Participants were purposively selected from five vocational and technical health care schools in Northern Taiwan representing the departments of nursing, gerontological care and management, and nutrition and health. Data were collected from five self-report questionnaires regarding teaching, the school environment, and creativity. Data were analyzed using Pearson's correlation coefficient and simple and hierarchical multiple regression models.

Results: A total of 53 teachers completed the questionnaires. Pearson's correlation analysis showed the teamwork component of school creative climate was correlated with the creative teaching behavior of characteristics and motivations. The mediation model indicated creative teaching self-efficacy fully mediated the effect of teamwork on teachers' characteristics and motivations. The moderation model indicated that teamwork negatively moderated the effect of teachers' creative teaching abilities for characteristics and motivations on creative teaching behaviors $(\beta=-0.01, p<0.001)$.

Conclusions: Our findings fill a gap in the literature regarding creative teaching behaviors and school climate in Taiwan. School teachers' creative teaching self-efficacy and creative teaching abilities are crucial mediating and moderating variables on the relationship between school creative climate and creative teaching behaviors, respectively. The empirical data confirm the validity of our proposed mediation and moderation models of creative teaching behaviors. Therefore, our findings may be effective references for health care teachers regarding creative teaching. Improving creative teaching behaviors of teachers responsible for educating students in health care schools could be facilitated by enhancing teachers' creative self-efficacy and creative abilities.

Keywords: Creative teaching behaviors, Mediated effects, Moderated effects, Health care school teachers

\footnotetext{
* Correspondence: hyliu@mail.cgust.edu.tw

${ }^{1}$ School of Nursing, Chang Gung University of Science and Technology, No.

261, Wunhua 1st Rd., Gueishan Township, Taoyuan, Taiwan, Republic of

China33303

${ }^{2}$ Associate Research Fellow, Chang Gung Memorial Hospital Taiwan; No. 261,

Wunhua 1st Rd., Gueishan Township, Taoyuan, Taiwan, Republic of

China33303
}

(c) The Author(s). 2019 Open Access This article is distributed under the terms of the Creative Commons Attribution 4.0 International License (http://creativecommons.org/licenses/by/4.0/), which permits unrestricted use, distribution, and reproduction in any medium, provided you give appropriate credit to the original author(s) and the source, provide a link to the Creative Commons license, and indicate if changes were made. The Creative Commons Public Domain Dedication waiver (http://creativecommons.org/publicdomain/zero/1.0/) applies to the data made available in this article, unless otherwise stated. 


\section{Background}

The Taiwanese government mandated that schools must foster creativity in students at all educational levels (White Paper on Creative Education, Taiwan's Ministry of Education, 2001). As a result, technical institutes and vocational schools in Taiwan have integrated creativity, innovation, and entrepreneurship into capstone courses since 2006. These courses include healthcare productbased curricula, which numerous health care schools, including nursing programs, have introduced to help students develop creative and innovative abilities in order to solve healthcare problems [1].

Despite the importance of teaching creativity in Taiwanese nursing schools, not every healthcare school teacher is gifted with creativity [2]. Therefore, understanding factors that influence a teacher's ability to teach creativity could improve student outcomes. Unfortunately, Unfortunately, most research on optimizing teaching creativity in healthcare education has focused on the students [3-7]. Only two recent studies have examined factors influencing the ability of nursing faculty in Taiwan to teach creativity in healthcare education $[2,8]$. Because of the rapid changes in global health care, the Taiwanese government has elected to enrich and enhance the ability of teachers to teach creativity; thus, examining factors that influence creative teaching behaviors in health care schools in Taiwan is crucial.

The concept of creativity is not well-defined and is dependent upon the context in which it is being evaluated $[8,9]$. Teachers in professional healthcare schools need to teach material creatively in order to help students develop new healthcare products to meet the demands of the growing healthcare market [1]. The measure of creativity can be influenced by social climate or the physical environment of an organization [9]. Therefore, in Taiwan, technology schools often depend on the Creativity Teaching Efficiency of Technology Institute Teacher's Scale (CTETITS) as a measure of a teacher's creativity [1]. The CTETITS was designed to specifically address aspects of creative abilities considered to be important for helping technology students successfully develop patentable products.

Several empirical studies have demonstrated a positive relationship between organizational climate and an individuals' creative and innovative behavior [10-12]. Thus, the creative climate of an academic setting is crucial for promoting creative teaching behaviors [13].

Tierney and Farmer (2002) added the construct of creative self-efficacy as an additional component of creativity [14]. This component measures the level of a person's belief in their ability to be creative in their work role. Several studies have reported that creative self-efficacy in teaching is positively related to creative teaching behaviors [15-19]. Creative self-efficacy has been shown to have a significant effect on creative behaviors of manufacturing employees $[14,20]$ and a significant mediating role of creative selfefficacy predicted employees' creativity [20].

Bandura suggested levels of self-efficacy are also influenced by components of the organizational climate [21]. Several studies have confirmed that a supportive school climate positively influences teachers' beliefs regarding self-efficacy [22, 23]. Moreover, individuals with high levels of creative self-efficacy exhibit creative behavior when they are in a climate that is supportive of innovation [24]. One can apply these findings to understanding creative teaching: a creative school climate can influence creative teaching behaviors through creative teaching self-efficacy.

A work environment that supports a creative climate plays a crucial role in motivating creativity [24-26]. However, a recent study in Taiwan by Chiu (2017) demonstrated creative teaching behaviors that encouraged diverse viewpoints and adopted diverse evaluations, failed to effectively enhance students' creativity [27]. Chiu suggested the inability to enhance students' creativity may have been due to the teacher's perception that the organizational climate was not innovative, resulting in a reduction in creative teaching self-efficacy, and a negative effect on the effectiveness of creative teaching behaviors [27]. This suggests that creative teaching selfefficacy and a school's creative climate have a relationship with creative teaching behaviors.

Taken together, these studies suggest a school's creative climate can influence creative teaching behaviors through creative teaching self-efficacy. The previous findings also suggest there is an effect of the interaction between a school's creative climate and teaching selfefficacy on creative teaching behaviors. Therefore, this study examined how fostering creativity in Taiwanese healthcare schools might be affected by the potential moderating and mediating roles of the relationship between (1) creative teaching self-efficacy and creative teaching behaviors and (2) a school's creative climate and creative teaching behaviors. The following two hypotheses guided this research:

Hypothesis 1: Creative teaching self-efficacy mediates the relationship between school creative climate and creative teaching behaviors in healthcare schools. Hypothesis 2: School creative climate moderates the relationship between creative teaching ability and creative teaching behaviors in healthcare schools.

\section{Proposed conceptual framework}

The aforementioned findings on creative teaching selfefficacy informed the proposed conceptual framework for the hypothetical model of our study. We examined two sets of interactions. First, based on Bandura's theory 
of self-efficacy [19], we examined whether creative teaching self-efficacy (CTS) would have a mediating effect (partially or fully) on the relationship between school creative climate (SCC) and creative teaching behaviors (CTB) (Fig. 1a). Second, based on Litwin and Stringer's creative climate model for work environments [28], we hypothesized that school creative climate would have a moderating effect on the association between creative teaching ability and creative teaching behaviors (Fig. 1b). Therefore, teachers with high levels of creative teaching ability in a school with a high level of creative climate should exhibit high levels of creative teaching behaviors. Whereas teachers with high levels of creative teaching ability in schools with low levels of creative climate should exhibit low levels of creative teaching behaviors.

\section{Methods}

\section{Design}

A cross-sectional quantitative design with structured questionnaires was used for this study.

\section{Participants and setting}

Teachers were selected by purposive sampling. An email was sent to four professional healthcare schools in Taiwan asking any teachers interested in participating in the study to respond. A total of 64 teachers expressed interest in participating. We used G*Power to calculate the required minimum sample size and set the confidence level as $95 \%$, the power of test as 0.8 , and the number of predictor variables as 3 . Subsequently, the minimum sample size required was determined to be 52 [29]. Teachers who expressed interest in participating received a packet containing a description of the study design and purpose, a consent form, and survey questionnaires. Teachers were instructed to sign the enclosed consent form, fill out the questionnaires, and return the packets by mail. Anonymity of the data was maintained by assigning a coding number to each packet. A total of 53 completed packets were returned for a response rate of $82.9 \%$. Participants were employed in the departments of nursing, gerontological care and management, and nutrition and health; the mean age was 49 years (standard deviation $[\mathrm{SD}]=4.73$ ); most were female (96\%). Approximately $38 \%$ of the teachers had at least 19 years of teaching experience. Approximately two-thirds (62\%) of the teachers had 3 or more years of creativity teaching experience. In addition, approximately $53 \%$ of the teachers had received at least $10 \mathrm{~h}$ of creativity training. Slightly over three-quarters $(78 \%)$ of the teachers expressed an interest in teaching creativity courses.

\section{Data collection}

Data were collected between October 2016 and January 2017 from survey questionnaires. One questionnaire was used to obtain data regarding participants' demographics (age, gender) and teaching characteristics (teaching experience, creativity training, and interest in teaching creativity courses). Four self-report questionnaires were used to collect data regarding creative teaching abilities (CTA), creative self-efficacy (CSE), creative teaching behaviors (CTB)and school creative climate (SCC). Measurements were determined using the self-report instruments described below.

\section{Measurements \\ School creative climate}

School creative climate was assessed with the School Creative Climate Scale (SCCS), which is an author developed scale modified from the Creativity Working Environment Scale [26]. The SCCS contains statements regarding four qualities of school climate: school encouragement (SE), school support (SS), team cooperation (TC), and sufficient resources (SR). Statements are scored using a 5 -point Likert scale from $1=$ never to $5=$ always. Higher scores indicate greater support for creativity. Factor analysis for this study showed that the communality values for the constructs of the SCCS were between 0.578 and 0.912 and the cumulative variation explained by the SCCS was $82.41 \%$. Cronbach's alpha

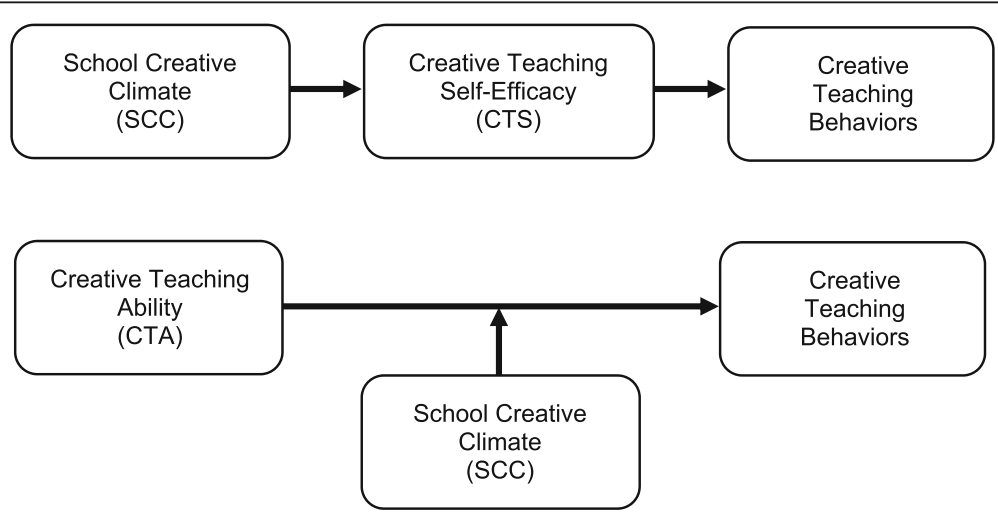

Fig. 1 Hypothesized models for mediating (a) and moderating (b) effects of creative teaching variables 
coefficient was computed to determine the reliability estimates of the SCCS for this study, which was 0.76 . The results indicated that the SCCS had satisfactory validity and reliability. The four statements for the SCCS are shown in Table 1.

\section{Creative teaching behavior (CTB)}

The Creative Teaching Behavior Scale (CTBS) measured teachers' creative teaching behavior. The CTBS is based on the 14-item Creativity Fostering Teacher Behavior Index developed by Soh [23]. Four subscales measure the following teaching behaviors: autonomous learning $(\mathrm{AL})$, creative thinking $(\mathrm{CT})$, characteristics/motivation $(\mathrm{CM})$, and environment/opportunity (EO), which are similar to Amabile's four components of creativity [24, 25]. AL (four items) determines how teachers foster a student's independent learning, which involves providing opportunities for exploration, self-teaching, and learning. CT (four items) assesses a teacher's ability to encourage and explain creative thinking, which includes creative approaches to problem solving as well as obstacles to creativity. CM (four items) determines how teachers encourage students to master basic requirements and approach conflict situations with a positive attitude. EO (two items) is the effort a teacher makes to foster student creativity in small groups through cooperation and interpersonal interactions. Items are scored with a 5point Likert scale: $1=$ never to $5=$ always. The subscale score is the mean score for the items; total score is the mean across all four subscales. Cronbach's alpha for the CTBS was 0.91 , and satisfactory validity was established for this scale through factor analysis [11]. In this study the Cronbach's alpha was 0.89 . Table 1 contains example statements for the subscales of the CTBS.

\section{Creative teaching self-efficacy (CTS)}

We measured creative teaching self-efficacy with the total score for the SECTS, developed by Lin and Chou [9]. The SECTS self-report instrument uses statements to measure three personality traits associated with creative teaching

Table 1 Examples of statements for subscale measures of creativity. The range for all statements is $1-5$

\begin{tabular}{|c|c|}
\hline Scale & Example statement \\
\hline \multicolumn{2}{|l|}{ SCCS subscales (4) } \\
\hline School encouragement (SE) & $\begin{array}{l}\text { Schools encourage teachers to engage in creative work through } \\
\text { public praise or rewards. }\end{array}$ \\
\hline School support (SS) & The school supports the creative ideas of the students. \\
\hline Team cooperation (TC) & Students can exchange ideas with each other without reservation. \\
\hline Sufficient recourses (SR) & The school provides sufficient supplies for developing healthcare products. \\
\hline \multicolumn{2}{|l|}{ CTBS subscales (4) } \\
\hline Autonomous learning $(A L)$ & I provide instruction to students on methods to improve learning. \\
\hline Creative thinking $(C T)$ & $\begin{array}{l}\text { I explain to students about obstacles and frustrations that are part } \\
\text { of the process of creativity. }\end{array}$ \\
\hline Characteristics/motivation (CM) Environment/opportunity (EO) & $\begin{array}{l}\text { I provide challenging and exciting materials to my students in accordance } \\
\text { with their abilities, to help them master required skills. } \\
\text { I encourage students to communicate with other members with positive } \\
\text { language in group. }\end{array}$ \\
\hline \multicolumn{2}{|l|}{ SECTS subscales (3) } \\
\hline Positive self-appraisal (SA) & $\begin{array}{l}\text { I can guide students to use creative thinking strategies to develop } \\
\text { their creativity. }\end{array}$ \\
\hline Lack of negative consciousness (NC) & I have enough creativity knowledge for teaching work. \\
\hline Belief in one's resistance to stress (BRS) & $\begin{array}{l}\text { I can actively develop student creativity with my teaching, even if the } \\
\text { school atmosphere is not conducive to creativity. }\end{array}$ \\
\hline \multicolumn{2}{|l|}{ CTETITS subscales (6) } \\
\hline Ability to evaluate patents and trademarks (EPT) & I encourage students to use their imagination to create trademark designs. \\
\hline Ability to teach about patents (ATP) & After my teaching, the students' works are more creative. \\
\hline Ability to teach creatively (ATC) & I appreciate the students' creations and provide additional rewards \\
\hline Knowledge of intellectual property rights (KIPR) & $\begin{array}{l}\text { My teaching results in a higher likelihood of my students' obtaining property } \\
\text { rights for the product they created. }\end{array}$ \\
\hline Ability to design courses (ADC) & My curriculum design can enhance students' creativity. \\
\hline Belief in the creativity of students (BCS) & I think that students' creativity can be nurtured. \\
\hline
\end{tabular}

Note: SCCS School's Creative Climate Scale, CTBS Creative Teaching Behavior Scale, CTETIS Creativity Teaching Efficiency of Technology Institute Teacher's Scale, SECTS Self-efficacy for Creative Teaching Scale 
self-efficacy: positive self-appraisal (SA, seven statements), lack of negative consciousness ( $\mathrm{NC}$, five statements), and belief in one's resistance to stress (BRS, three statements). The statements are scored with a 5-point Likert scale; $1=$ strongly disagree to $5=$ strongly agree. The total score is the average of the sum of the three subscale scores (range $=1-5$ ); a higher score indicates a greater level of creative teaching self-efficacy. The average total score has been reported to be 3.94; the average score for the three subscales is between 3.51 and 4.34 [9]. Cronbach's alpha coefficient for the SECTS is 0.92 . Confirmatory factor analysis (CFA) showed the factor loadings for the statements for SA, NC, and BRS were 0.632-0.905, 0.615-0.835, and $0.769-0.98$, respectively. The composite reliability (CR) for the SA, NC, and BRS was 0.906, 0.805, and 0.917, respectively; the average variance extracted (AVE) of the SA, $\mathrm{NC}$, and BRS was 0.58, 0.584, and 0.789, respectively. Therefore, CFA established satisfactory validity for the SECTS instrument. Reliability of the SECTS for this study, determined by Cronbach's alpha coefficient, was 0.76 . Examples of statements used to measure the three traits of the SECTS are shown in Table 1.

\section{Creative teaching ability (CTA)}

Creative Teaching Ability (CTA) was measured with the total score of the Creative Teaching Efficiency of Technology Institute Teacher's Scale (CTETITS) [2]. The CTETITS is a 31-item self-report instrument used to assess abilities considered important for teaching technology creatively. Four abilities are measured with the following subscales: evaluate patents and trademarks (EPT; 11 items), teach about patents creatively (TPC;), ability to teach creatively (ATC; 5 items), knowledge of intellectual property rights (KIPR; 7 items), creatively design courses (CDC; 3 items), and ability to believe in the creativity of students (BCS; 2 items). Each item is represented by a statement and scored on a 5-point Likert scale. For example, the EPT item states, "My ability to evaluate patents and trademarks is excellent"; 1 = strongly disagree; $2=$ disagree; $3=$ neutral; $4=$ agree; or $5=$ strongly agree. The total score for the CTETITS is the average of the sum of the six abilities; higher scores indicate a greater perceived ability to teach technology creatively. The average total score has been reported to be 3.57 ; average subscale scores for qualities range from 3.22 to 4.09 [2]. Cronbach's alpha coefficient for the CTETITS is 0.97 . Factor analysis established satisfactory validity for the scale [2]. Reliability of the CTETITS for this study, determined by Cronbach's alpha coefficient was 0.93 . Table 1 shows examples of statements for each subscale.

\section{Reliability of the instruments}

Table 2 shows the Cronbach's $\alpha$ coefficients for the four scales and subscales used in this study. The SCCS, CTBS,
SECTS, and CTETITS measure school creative climate, creative teaching behaviors, creative teaching self-efficacy, and creative teaching ability, respectively. All Cronbach's $\alpha$ coefficients are greater than 0.7 , indicating the scales and subscales have satisfactory reliability.

\section{Data analysis}

After all packets were collected, data were entered into a computer and analyzed using SPSS version 20.0. Descriptive statistics using the mean and standard deviation (SD) evaluated the characteristic of the participants. Analysis with Pearson's correlation coefficient identified correlations between school creative climate, creative teaching behaviors, creative teaching ability and creative teaching self-efficacy. Subsequently, stepwise linear regression and hierarchical multiple regression were performed to test the mediating and moderating effects of creative teaching ability and creative teaching self-efficacy on school creative climate and creative teaching behavior.

\section{Results \\ Mean scale scores and correlation for SCCS, CTBS, SECTS, and CTETIS}

Mean scale scores for the 53 teachers in our study are shown in Table 3. The total score for the CTBS was highest (mean $=4.35, \mathrm{SD}=0.47$ ), and autonomous learning was the highest subscale score $(4.56, \mathrm{SD}=0.47)$ suggesting a high level of creative teaching behaviors for teachers. The SCCS had the lowest mean score (mean = $3.61, \mathrm{SD}=0.70$ ) as well as a low subscale score for sufficient resources $($ mean $=2.78, \mathrm{SD}=1.15)$. Mean scores for creative teaching self-efficacy (SECTS) and creative teaching ability (CTETIS) were similar ( mean $=3.76$, $\mathrm{SD}=0.50$ and mean $3.95, \mathrm{SD}=0.48$, respectively).

Analysis of Pearson's correlations was conducted to determine if there were any relationships between measures for teachers' school creative climate, as measured with subscales of the SCCS, creative teaching behaviors, measured with subscales of the CTBS, total SECTS scores as measures of creative teaching self-efficacy, and total score for the CTETIS, as a measure of creative teaching ability (Table 4). Correlations were determined using the method of Cohen (1992) [29]. The teamwork (TW) subscale of the SCCS was moderately correlated with the CTBS subscale of characteristics and motivations (CM) $(\mathrm{r}=0.35, p<.01)$, suggesting a relationship between these aspects of creative school climate and creative teaching behaviors, respectively. Teachers' creative teaching ability (CTA) was correlated with creative teaching behavior; the total score for the CTA and all four subscales of the CTBS was moderate $(\mathrm{EO}, \mathrm{r}=.32 ; p<.05)$ to high (Al, $\mathrm{r}=.58 ; \mathrm{CT}, \mathrm{r}=.60 ; \mathrm{CM}$, $\mathrm{r}=0.78 ; \mathrm{p}<.01$ ). The total score for the SECTS was significantly correlated with three subscales of the CTBS $(\mathrm{p}<.01): \mathrm{AL}, \mathrm{r}=.33 ; \mathrm{CT}, \mathrm{r}=.36 ;$ and $\mathrm{CM}, \mathrm{r}=.63$, 
Table $\mathbf{2}$ Cronbach's alpha coefficients of the scales and subscale of the instruments

\begin{tabular}{|c|c|}
\hline Instrument & $\begin{array}{l}\text { Cronbach's } \\
\text { a-coefficient }\end{array}$ \\
\hline \multicolumn{2}{|l|}{ School Creative Climate Scale (SCCS) } \\
\hline Total scale (15 items) & 0.76 \\
\hline \multicolumn{2}{|l|}{ Subscales } \\
\hline School encouragement (SE; 4 items) & 0.89 \\
\hline School support (SS; 5 items) & 0.76 \\
\hline Teamwork (TW; 3 items) & 0.91 \\
\hline Sufficient resources (SR; 3 items) & 0.93 \\
\hline \multicolumn{2}{|l|}{ Creative Teaching Behavior Scale (CTBS) } \\
\hline Total scale (14 items) & 0.81 \\
\hline \multicolumn{2}{|l|}{ Subscales } \\
\hline Autonomous learning (AL; 4 items) & 0.83 \\
\hline Creative thinking ( $\mathrm{CT} ; 4$ items) & 0.77 \\
\hline Characteristics and motivations (CM; 4 items) & 0.87 \\
\hline Environment and opportunity (EO; 2 items) & 0.70 \\
\hline \multicolumn{2}{|l|}{ Self-Efficacy for Creativity Teaching Scale (SECTS) } \\
\hline Total (15 items) & 0.81 \\
\hline \multicolumn{2}{|l|}{ Subscales } \\
\hline Self-affirmation (SA; 7 items) & 0.90 \\
\hline Negative consciousness (NC; 4 items) & 0.73 \\
\hline Stress resistant beliefs (SRB; 4 items) & 0.75 \\
\hline \multicolumn{2}{|l|}{$\begin{array}{l}\text { Creativity Teaching Efficiency of Technology } \\
\text { Institute Teachers Scale (CTETITS) }\end{array}$} \\
\hline Total scale (31 items) & 0.93 \\
\hline \multicolumn{2}{|l|}{ Subscales } \\
\hline $\begin{array}{l}\text { Evaluate patents and trademarks creatively } \\
\text { (EPTC; } 11 \text { items) }\end{array}$ & 0.92 \\
\hline Teach patents creatively (TPC; 3 items) & 0.83 \\
\hline Ability to teach creatively (ATC; 5 items) & 0.83 \\
\hline Knowledge of intellectual property rights (KIPR; 7 items) & 0.77 \\
\hline Creatively design courses (CDC; 3 items) & 0.86 \\
\hline Believe in the creativity of students (BSC; 2 items) & 0.91 \\
\hline
\end{tabular}

suggesting a relationship between creative teaching selfefficacy and creative teaching behaviors, with the exception of environment and opportunity.

Mediation analysis for teachers' creativity teaching selfefficacy on school creative climate and creative teaching behavior

Analysis with Pearson's correlation coefficients, shown in Table 4, indicated only the SCCS subscale of teamwork, was correlated with the CTBS subscale of characteristics and motivations. This suggested a potential mediator existed for these two variables. Therefore, we examined whether the relationship of a school creative climate of teamwork (TW) and the creative teaching behavior of
Table 3 Mean scale and subscale scores for teachers ( $N=53)$

\begin{tabular}{lll}
\hline Scale & Mean score & SD \\
\hline SCCS & 3.61 & 0.70 \\
Total & & \\
Subscale & 3.79 & 0.90 \\
SE & 3.75 & 0.85 \\
SS & 3.97 & 0.66 \\
TW & 2.78 & 1.15 \\
SR & & \\
CTBS & 4.35 & 0.47 \\
Total & & \\
Subscale & 4.56 & 0.47 \\
AL & 4.43 & 0.52 \\
CT & 4.11 & 0.67 \\
CM & 4.25 & 0.70 \\
EC & 3.76 & 0.50 \\
SECTS (total) & 3.93 & 0.48 \\
CTETITS (total) & &
\end{tabular}

characteristics and motivations (CM) were mediated by a teacher's creative teaching self-efficacy. Following the guidelines suggested by Baron and Kenny [30] an analysis of mediation was performed. Prior to conducting the mediation analysis, we examined the variables for multicollinearity. As shown in Table 4, no correlation coefficient exceeded 0.8 , indicating there was no multicollinearity [31].

We used the multiple regression approach recommended by Baron and Kenny [30] to determine if creative teaching self-efficacy mediated TW and CM. Table 5 summarizes the parameters for the multiple regression models. In Model 1, we regressed teachers' characteristics and motivations on teamwork; the coefficient for teamwork was positive and significant $(\beta=0.35, p<.05)$. Next, in Model 2 we regressed teachers' creative teaching selfefficacy on teamwork; and found that it was positive and significant $(\beta=0.34, \mathrm{p}<.05)$. To meet the third requirement for mediation, we regressed characteristics and motives on teamwork and creative teaching self-efficacy (Model 3). Teachers' creative teaching self-efficacy was positively and significantly related to teachers' characteristics and motives $(\beta=0.57, p<.001)$; teamwork was positive but not significant $(\beta=0.16, p=0.18)$. Therefore, our results indicated that teachers' creative teaching selfefficacy fully mediated the effect of teamwork on teachers' characteristics and motivations.

Moderation analysis for school creative climate on teachers' creative teaching ability and creative teaching behavior

Before conducting the regression analysis for moderating effects, we used mean centering (subtracting raw scores 
Table 4 Correlations among participants' subscale scores of the School Creative Climate Scale (SCCS) and Creative Teaching Behavior Scale (CTBS), and total scores for Self-efficacy for Creative Teaching Scale (SECTS) and Creative Teaching Efficiency of Technology Institute Teacher's Scale (CTETITS)

\begin{tabular}{|c|c|c|c|c|c|c|c|c|c|c|}
\hline \multirow[t]{2}{*}{ Instrument/Subscale } & \multicolumn{4}{|l|}{ SCCS } & \multicolumn{4}{|l|}{ CTBS } & \multirow{2}{*}{$\begin{array}{l}\text { SECTS } \\
9\end{array}$} & \multirow{2}{*}{$\begin{array}{l}\text { CTETITS } \\
10\end{array}$} \\
\hline & 1 & 2 & 3 & 4 & 5 & 6 & 7 & 8 & & \\
\hline \multicolumn{11}{|l|}{ SCCS } \\
\hline 1. School encouragement (SE) & - & & & & & & & & & \\
\hline 2. School support (SS) & $.73^{* *}$ & - & & & & & & & & \\
\hline 3. Teamwork (TW) & $.33^{*}$ & $.31^{*}$ & - & & & & & & & \\
\hline 4. Sufficient resources (SR) & $.45^{* *}$ & $.56^{* *}$ & .20 & - & & & & & & \\
\hline \multicolumn{11}{|l|}{ CTBS } \\
\hline 5. Autonomous learning (AL) & .15 & .18 & .05 & .18 & - & & & & & \\
\hline 6. Creative thinking $(\mathrm{CT})$ & -.01 & .04 & .08 & .18 & $.72^{* *}$ & - & & & & \\
\hline 7. Characteristics and motivation (CM) & .22 & .19 & $.35^{* *}$ & .07 & $.64^{* *}$ & $.64^{* *}$ & - & & & \\
\hline 8. Environment and opportunity (EO) & .05 & .27 & .06 & .26 & $.43^{* *}$ & $.46^{* *}$ & .27 & - & & \\
\hline 9. SECTS & .13 & .24 & $.34^{*}$ & .20 & $.33^{*}$ & $.36^{* *}$ & $.63^{* *}$ & .05 & - & \\
\hline 10. CTETITS & .04 & .01 & .24 & -.03 & $.58^{* *}$ & $.60^{* *}$ & $.78^{* *}$ & $.32^{*}$ & $.53^{* *}$ & - \\
\hline
\end{tabular}

Note: Total score for SECTS measures creative teaching self-efficacy; total score for the CTETITS measures creative teaching ability. ${ }^{*} p<.05,{ }^{* *} p<.01$

from the mean) to avoid multicollinearity. To determine whether a moderated relationship existed, we regressed teachers' characteristics and motivations on teamwork, teachers' creative teaching ability, and its interaction with teamwork (TW x CTA) using the PROCESS macro available for SPSS and SAS [32]. Table 6 and Fig. 2 show the results of our regression analysis. Table 6 shows the coefficient $\beta$ was insignificant for teamwork $(\beta=0.13$, $p=0.16)$. However, the coefficient was significant for creative teaching ability $(\beta=0.11, p<.001)$; there was a negative interaction between teamwork and creative teaching ability (TW x CTA) $(\beta=-0.01, p<0.001)$.

The graph in Fig. 2 shows the intersection between creative teaching abilities for low, medium, and high levels of teamwork. These results confirm teamwork had a moderating effect on the relationship between creative teaching abilities and characteristics and motivations.

\section{Discussion}

This study examined the mediating and moderating effects of Taiwanese health care school teachers' creative teaching ability and teaching self-efficacy on the association between school creative climate and creative teaching behaviors. Our findings indicated that creative school climate is a crucial component for creative teaching behavior, which is in agreement with a prior study by Hsu et al. [13]. In addition, our findings revealed that teachers' creative self-efficacy can predict creative teaching behaviors; this result was in agreement previous reports $[16,17]$.

When we examined models for mediating effects, health care school teachers' creative teaching selfefficacy fully mediated the predictive association between school creative climate and creative teaching behaviors. Specifically, the association between teamwork and characteristics and motivations was fully mediated by creative teaching self-efficacy. Therefore, Hypothesis 1 was confirmed; the relationship between school creative climate and creative teaching behaviors in healthcare schools is mediated by creative teaching self-efficacy. Our findings suggest teamwork plays an important role in school creative climate, by influencing teachers' creative teaching behaviors of characteristics and motivations. Therefore, health care schools should encourage a culture of teamwork and mutual support as part of the school's creative climate in order to enhance creative

Table 5 Parameters for the regression analysis of creative teaching self-efficacy (CTS) as a mediator for teamwork (TW) and characteristics and motivations (CM)

\begin{tabular}{|c|c|c|c|c|c|}
\hline Parameter & CTS (mediator) & CM (criterion) & $\Delta \mathrm{F}$ & Adjusted $R^{2}$ & $\Delta R^{2}$ \\
\hline Model $1 ;$ predictor $=$ TW & & $0.35^{*}$ & $7.23^{* *}$ & 0.11 & 0.12 \\
\hline Model 2; predictor $=$ TW & $0.34^{*}$ & & $6.67^{*}$ & 0.10 & 0.12 \\
\hline Model 3; predictor $=$ TW & & 0.16 & $17.62^{* * *}$ & 0.39 & 0.41 \\
\hline Model 3; mediator $=$ CTS & & $0.57^{* * *}$ & & & \\
\hline
\end{tabular}

Note: ${ }^{*} p<.05,{ }^{* *} p<.01,{ }^{* * *} p<.001$ 
Table 6 Parameters for moderated regression analysis of teamwork (TW) and creative teaching ability (CTA)

\begin{tabular}{lllll}
\hline Variable & $\beta$ & s.e. $(\beta)$ & $\mathrm{t}$ & $p$-value \\
\hline Constant & $16.55[16.11,16.98]$ & 0.22 & 76.65 & $p<0.001$ \\
TW (centered) & $0.13[0.05,0.32]$ & 0.09 & 1.43 & $p=0.16$ \\
CTA (centered) & $0.11[0.09,0.12]$ & 0.01 & 14.31 & $p<.001$ \\
TW $\times$ CTA & $-0.01[-0.01,0.00]$ & 0.01 & -3.87 & $p<.001$ \\
\hline
\end{tabular}

teaching behaviors, which could improve health care students' creativity.

The school creative climate variable of teamwork had a moderate $(\beta=0.34)$ direct effect on teachers' creative teaching self-efficacy; teachers' creative teaching selfefficacy had a large $(\beta=0.57)$ direct effect on the creative teaching behavior variable of characteristics and motivations. The indirect (mediated) effect of teamwork on teachers' characteristics and motivations was small $(\beta=$ 0.16). Moreover, characteristics and motivations explained $10 \%$ of the variance for teamwork (adjusted $R^{2}=0.10$ ). When this was added to creative teaching self-efficacy, characteristics and motivations increased the variance to $39 \%$ (adjusted $R^{2}=0.39$ ). This result suggests that creative teaching self-efficacy mediates the association between characteristics and motivations and teamwork among health care teachers. These findings suggest that interventions targeted at improving teachers' levels of creative teaching self-efficacy may help health care schools with low levels of teamwork stimulate teachers' creative teaching behaviors involving characteristics and motivations.

When we examined models for moderating effects, we found school creative climate moderated the relationship between creative teaching ability and creative teaching behavior. These findings confirm Hypothesis 2: the relationship between creative teaching ability and creative teaching behaviors for health care school teachers is moderated by creative school climate. This result is in agreement with the findings of Hsu et al. (2011); creative teaching ability and school creative climate interacted in a manner to influence creative teaching behaviors among elementary, junior high, and senior high school teachers in Taiwan [13]. Interestingly, Hsu et al. identified only one of eight subscales for school creative climate (team operation) as a moderator. However, our findings are in contrast to those of Cayirdag (2017) who found no association between creative teaching behaviors and creative teaching ability [17].

Teamwork had a positive moderating effect on the interaction of teachers' creative teaching ability and the creative teaching behavior of characteristics and motivations. This finding suggests teachers with lower levels of creative teaching ability in a school climate with a high level of teamwork should demonstrate stronger creative teaching behaviors. Teamwork had a negative moderating effect on the interaction of creative teaching abilities and creative teaching behaviors involving characteristics and motivations. This suggests teachers with lower creative teaching abilities would demonstrate lower creativity teaching behaviors when they perceive the school climate does not encourage teamwork.

Our study findings fill a gap in the literature regarding the interactions between a school's environment and how a teacher's creativity might be fostered. A school's creative climate and creative teaching behaviors of the teaching staff could be the focus of developing strategies for improving creative teaching self-efficacy. Our findings also

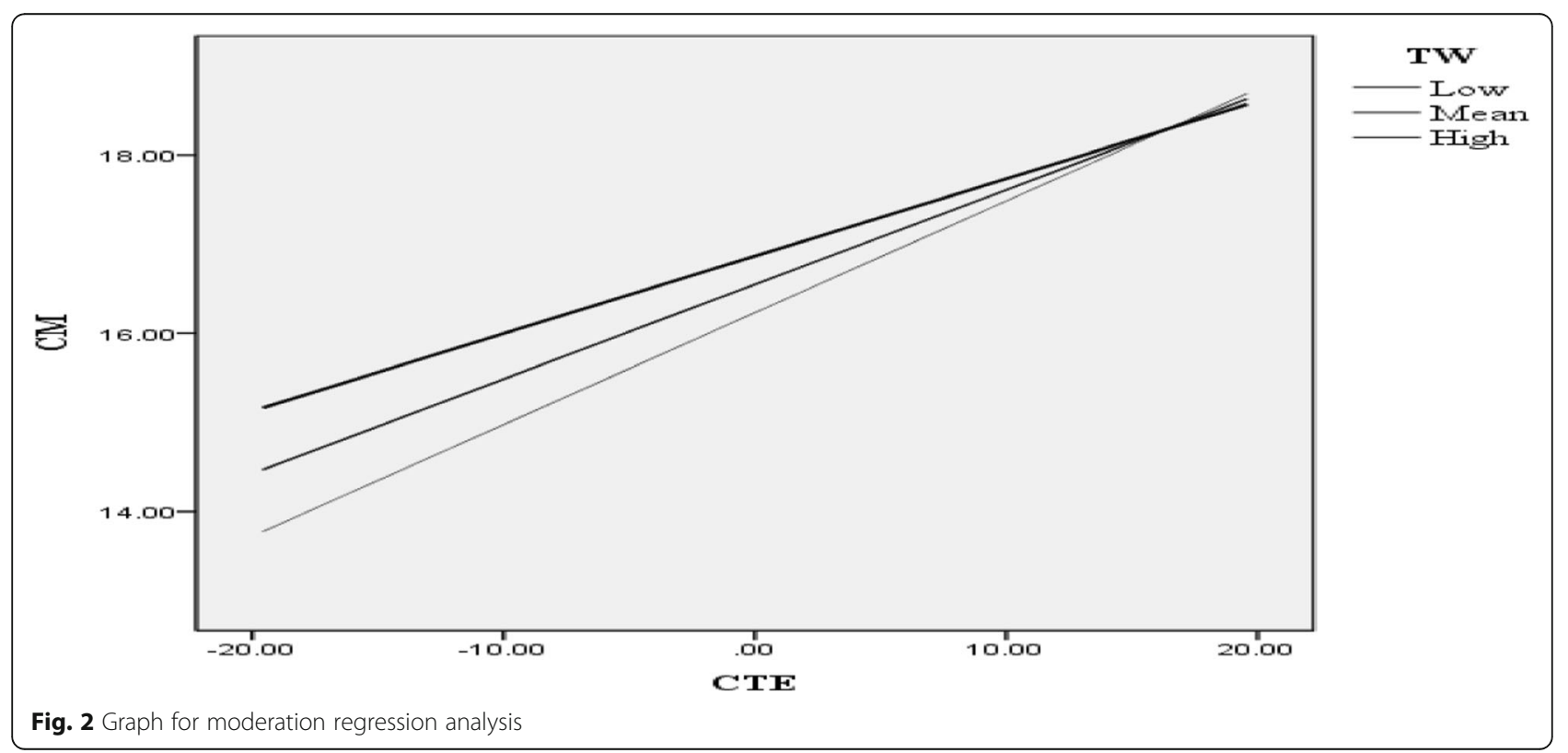


suggest that teachers with high levels of creativity teaching ability are more likely to exhibit high levels of creative teaching behaviors.

\section{Practical implications}

The results presented here have implications for health care school teachers in Taiwan. The mediating and moderating roles of creative teaching self-efficacy and teaching abilities should be considered when examining how to improve a school's creative climate and teachers' creative teaching behaviors. The mediation and moderation models of creative teaching behavior could be effective references for improving health care teachers' creative teaching. Enhancing teachers' creativity, teaching selfefficacy and teaching abilities may be crucial for implementing creativity in health care schools.

The capstone courses for innovative and patentable healthcare products are designed to help nurses become competitors in the international market and solve realworld problems in healthcare (Ku et al., 2014) [5, 6]. Therefore, it is crucial for teaching faculty in nursing programs have knowledge about developing innovative products and applying for patents. Thus the use of the CTETITS was important in this study. One recent study by Liu et al. [1] showed low subscale scores on the CTETITS might be related to the number of hours of teacher training. The association between personality traits, as measured with the SECTS instrument and self-efficacy of teaching intellectual property rights, as measured with the CTETITS, should be further investigated by assessing student creativity as an outcome measure.

\section{Limitations}

This study had several limitations. First, the sample used was based on a cross-sectional descriptive study design with 53 health care school teachers in Taiwan, which limits the generalizability of our findings to health care teachers outside of Taiwan. However, our data were obtained from five health care schools in Taiwan offering capstone courses related to creativity, which provides a broad perspective within this population. Second, because creative teaching self-efficacy is likely to be a component of a multitude of mediational pathways involved in the association between school creative climate and creative teaching behavior, testing the role of other attributes as explanatory mechanisms is vital for future research. Third, it is a difficult task to compare our results with those of previous studies due to the focus of teaching for creativity of healthcare education is noticeably absent from the literature.

\section{Conclusions}

In this study, we explored the mediating and moderating effects of the relationship between school creative climate and creative teaching behaviors as well as the relationship between creative teaching ability and creative teaching behaviors that foster creativity for teachers in health care schools in Taiwan. Our study confirmed that health care school teachers' creative self-efficacy and school creative climate are crucial mediating and moderating variables on the relationship between school creative climate and creative teaching behaviors and between teachers' creative teaching ability and creative teaching behaviors that foster creativity, respectively. The proposed mediation and moderation models of creative teaching behavior were validated by the empirical data and can be used as references for health care teachers' creative teaching.

This study examined aspects of creative teaching behaviors from a quantitative perspective in or orders to establish a means of evaluating changes in behaviors that can be replicated in other teaching environments. To implement creative education in health care schools, enhancing teachers' creative teaching self-efficacy and developing creative school climates that encourage teamwork should be key considerations. The measurement scales here could be used to assess the success of such changes. However, additional information on how to implement creative education in health care schools could be gained by conducting qualitative studies to determine teachers' personal attitudes about creativity and how teamwork might be encouraged.

\section{Abbreviations \\ CTB: Creative teaching behaviors; CTETITS: Creativity Teaching Efficiency of Technology Institute Teacher's Scale; CTS: Creative teaching self-efficacy; SCC: School creative climate}

\section{Acknowledgements}

The authors wish to thank all study participants for their contribution to the research.

\section{Authors' contributions}

HYL conducted the literature review, prepared data for analysis, and wrote the first draft of the manuscript. ITW also contributed to literature review and analyzed the data. All authors participated in interpretation of data, as well as writing, editing and approval of the final manuscript.

\section{Funding}

This study was supported by a research grant from the Ministry of Science and Technology Taiwan R.O.C. (NMRPF3F0151). The funder had no role in the design and conduct of the study; the collection, analysis, and interpretation of the data; the preparation of the manuscript; or the decision to submit the manuscript for publication.

\section{Availability of data and materials}

The datasets used and/or analyzed during the present study available from the corresponding author on reasonable request.

\section{Ethics approval and consent to participate}

This study has approved the hospital ethics committees (104A010B, research ethics committee, Chang Gung Medical Foundation Institutional Review Board). Study participants completed an informed consent before beginning the survey Confidentiality was assured in the consent forms and the participants remained the right to withdraw their participations at any phase of the research process. 


\section{Competing interests}

The authors declare that they have no competing interests.

Received: 28 February 2019 Accepted: 29 May 2019

Published online: 04 June 2019

\section{References}

1. Liu HY, Wang IT, Hang HM, Hang DH, Hsu DY. Self-efficacy of teaching for creativity for nursing faculty in Taiwan: a preliminary study. Nurs Educ Perspect. 2019; in press.

2. Liu HY, Kuo CL, Shen MH, Lee PY, Lee PY, Ku YL. Evaluating faculties and students satisfaction of a nursing practicum project workshop in northern Taiwan. J Nur Res Pract. 2018;2(2):16-9.

3. Huang PS, Peng SL, Chen HC, Tseng LC, Hsu LC. The relative influences of domain knowledge and domain-general divergent thinking on scientific creativity and mathematical creativity. Think Skills Creat. 2017;25:1-9.

4. Hsu $Y$, Peng $L P$, Wang $J H$, Liang C. Revising the imaginative capability and creative capability scales: testing the relationship between imagination and creativity among agriculture students. Int J Learn Teach Educ Res. 2014;6(1):57-70.

5. Ku YL, Lee PY, Shen MH, Kuo CL. Constructing and evaluating a nursing capstone course for cultivating creativity in RN-BSN students in Taiwan. J Nurs Educ Pract. 2014;4(7):1-10.

6. $\mathrm{Ku}$ YL, Kuo CL. Develop a framework of creative thinking teaching mode for RN-BSN students on the basis of the creative process of clinical nurses in Taiwan. Inov Educ Teach Int. 2016;53:424-34.

7. Peng SL, Cheng BL, Chen HC. The effects of classroom goal structures on the creativity of junior high school students. Educ Psychol. 2013;33(5):540-60.

8. Ma X, Yang Y, Wang X, Zang Y. An integrative review: developing and measuring creativity in nursing. Nurs Educ Today. 2018;62:1-8.

9. Amabile TM. A model of creativity and innovation in organizations. Res Organ Behav. 1988;10(1):123-67.

10. Neal A, Griffin MA, Hart PM. The impact of organizational climate on safety climate and individual behavior. Saf Sci. 2000;34:99-109.

11. Zheng JJ, Jin SH, Ma GY. The measurement of organizational innovation climate and its moderating effect in the relationship between employees' innovation ability and innovation performance. Acta Psychologic Sinica. 2009:41:1203-14.

12. Jaiswal NK, Dhar RL. Transformational leadership, innovation climate, creative self-efficacy and employee creativity: a multilevel study. Int J Hosp Manag. 2015;51:30-41.

13. Hsu CW, Chang YL, Wu IC, Shu FP. Applications of hierarchical linear models on influence of creative climate of schools and effective teaching on creativity-teaching behaviors. Creative J. 2011;2:87-112.

14. Lin PF, Chiou HJ. Construction and related study of the inventory of selfefficacy for creative teaching. J Educ Res Dev. 2008;4:141-70.

15. Chang YL, Chen HC, Hsu CC. Belief of creativity and self-efficacy for creativity-teaching's effect on teaching behaviors for creativity. Fu Hsing Kang Acad J. 2010;99:151-72.

16. Ozkal N. Relationships between teachers' creativity fostering behaviors and their self-efficacy beliefs. Educ Res Rev. 2014;9(18):724-33.

17. Cayirdag N. Creativity fostering teaching: impact of creative self-efficacy and teacher efficacy. Educ Sci Theor Pract. 2017;17(6):1959-75.

18. Haase J, Hoff E, Hanel P, Innes-Ker A. A meta-analysis of the relation between creative self-efficacy and different creativity measurements. Creat Res J. 2018:30(1):1-16.

19. Bandura A. Self-efficacy mechanism in human agency. Am Psychol. 1982;37:122-47.

20. Meristo M, Eisenschmidt E. Novice teachers' perceptions of school climate and self-efficacy. Int J Educ Res. 2014;67:1-10.

21. Aldridge JM, Barry JF. Teachers' views of their school climate and its relationship with teacher self-efficacy and job satisfaction. Learn Environ Res. 2016;19(2):291-307.

22. Tierney P, Farmer SM. Creative self-efficacy: its potential antecedents and relationship to creative performance. Acad Manag J. 2002;45(6):1137-48.

23. Gong Y, Huang JC, Farh JL. Employee learning orientation, transformational leadership, and employee creativity: the mediating role of employee creative self-efficacy. Acad Manag J. 2009:52(4):765-78.

24. Jaiswal NK, Dhar RL. Transformational leadership, innovation climate, creative self-efficacy and employee creativity: a multilevel study. Int J Hospitality Manag. 2015;51:30-41.
25. Jaiswal NK, Dhar RL. Fostering employee creativity through transformational leadership: moderating role of creative self-efficacy. Creat Res J. 2016;28(3):367-71.

26. Wang P, Rode JC, Shi K, Luo Z, Chen W. A workgroup climate perspective on the relationships among transformational leadership, workgroup diversity, and employee creativity. Group Org Manag. 2013;38(3):334-60.

27. Chiu IC. A study on the relationship between innovative climate and innovative teaching among teachers' perceptions in elementary school in Taipei city. Forum of Educ Admin. 2017;9(1):28-48.

28. Litwin G, Stringer R. Motivation and organizational climate. Boston: Harvard University Press; 1968.

29. Cohen JA. Power primer. Psychol Bull. 1992:112:155-9.

30. Baron RM, Kenny DA. The moderator-mediator variable distinction in social psychological research: conceptual, strategic, and statistical considerations. J Pers Soc Psychol. 1986;51:1173-82.

31. Hair JF, Black WC, Babin BJ, Anderson RE. Multivariate data analysis. 7th ed. New Jersey: Prentice Hall; 2010.

32. Hayes AF. Introduction to mediation, moderation, and conditional process analysis: a regression-based approach. New York: Guilford; 2013. p. 207-44.

\section{Publisher's Note}

Springer Nature remains neutral with regard to jurisdictional claims in published maps and institutional affiliations.

\section{Ready to submit your research? Choose BMC and benefit from:}

- fast, convenient online submission

- thorough peer review by experienced researchers in your field

- rapid publication on acceptance

- support for research data, including large and complex data types

- gold Open Access which fosters wider collaboration and increased citations

- maximum visibility for your research: over $100 \mathrm{M}$ website views per year

At $\mathrm{BMC}$, research is always in progress.

Learn more biomedcentral.com/submissions 